\title{
Techniques of Functional and Motility Test: How to Perform and Interpret Intestinal Permeability
}

\author{
Asha Mishra and Govind K Makharia*
}

Department of Gastroenterology and Human Nutrition, All India Institute of Medical Sciences, New Delhi, India

Transport of molecules across the intestinal epithelium takes place through 2 major routes, ie, trans-cellular and paracellular. Assessment of intestinal permeability is performed to assess the overall function of transport through the intestinal epithelial paracellular route. Urinary excretion of disaccharides and monosaccharides and ratio of their excretion is a basis for measurement of intestinal permeability. Lactulose and mannitol ratio is the most commonly used test for assessment of small intestinal permeability and the most reliable method for measurement of concentration of lactulose and mannitol in the urine is high performance liquid chromatography. After the measurement of concentration of probes in the urine; the results are expressed as the ratio of percentage excretion of the ingested dose of lactulose and mannitol in the urine. Testing of intestinal permeability is not required for routine patient care, however it is an important tool to understand the function of the paracellular transport in the research setting. Increase in intestinal permeability has been implicated in the pathogenesis of many autoimmune diseases including celiac disease, Crohn's disease, type I diabetes and food allergy.

(J Neurogastroenterol Motil 2012;18:443-447)

Key Words

Autoimmune disease; Intestine, small; Lactulose; Mannitol

\section{Introduction}

\section{Principle of Intestinal Permeability}

Assessment of intestinal permeability is done to assess the overall function of transport through the intestinal epithelial paracellular route. ${ }^{1}$ Transport of molecules across the intestinal epithelium takes place through two major routes, ie, trans-cellular and paracellular. Transport of solutes across the transcellular route is carrier-mediated and occurs with the help of transporters and channels. Transport of molecules through paracellular route across the intestinal epithelium occurs by the process of diffusion and it is not carrier-mediated. Intact intestinal epithelial barrier is essential for preventing penetration of the intestinal mucosa by the noxious substances. The disruption of this barrier system results in "leaky" intestine leading to increase in intestinal permeability. $^{2}$ Intestinal permeability is the property of intestinal epi-

Received: September 21, 2012 Revised: September 25, 2012 Accepted: September 25, 2012

(c) This is an Open Access article distributed under the terms of the Creative Commons Attribution Non-Commercial License (http://creativecommons. org/licenses/by-nc/3.0) which permits unrestricted non-commercial use, distribution, and reproduction in any medium, provided the original work is properly cited.

*Correspondence: Govind K Makharia, MD, DM, DNB

Department of Gastroenterology and Human Nutrition, All India Institute of Medical Sciences, Ansari Nagar, New Delhi 110029 , India

Tel: +91-11-26588091 (or 26596546), Fax: +91-11-26588641 (or 26588663), E-mail: govindmakharia@gmail.com, govindmakharia@ aiims.ac.in

Financial support: None.

Conflicts of interest: None. 
thelium by which it allows the molecules to pass through by non-mediated diffusion. ${ }^{3}$

Intestinal permeability is mainly concerned with the permeation of molecules with a molecular weight greater than 150 $\mathrm{Da}^{3}$ There are series of aqueous pores along the crypt villous axis of the small intestine. ${ }^{4}$ While the tip of the villus contains relatively small $(<6 \AA$ ) pores and they are present in abundance, the crypts contain much larger pores (50-60 $\AA$ ) but they are in low abundance. The base of the villus contains intermediate size (10-15 $\AA$ ) pores. Most of the probes used to measure intestinal permeability are water-soluble, which cannot penetrate the lipid cell membrane of enterocytes and thus use the paracellular route through the tight junctions. The smaller probes can easily pass through the small, more numerous and more accessible tight junctions of the villous tips, whereas the larger probes have to make use of the larger, less accessible and less numerous pores at the crypt base.

\section{Non-invasive Technique for Measurement of Intestinal Permeability}

While the absorption of sugar (rhamnose, xylose and arabinose) as a test marker of intestinal functional assessment was first reported by McCance and Madders ${ }^{5}$ in 1930s, the assessment of human intestinal permeability was first reported by Fordtran et $\mathrm{al}^{6}$ in 1965. Later Menzies ${ }^{7}$ in 1974 introduced oligosaccharides as a test probe for non-invasive assessment of intestinal permeability.

Intestinal permeability is measured with the help of non-metabolizable probe (either by human gut or even by the bacteria present in the gut) molecules which pass across the mucosal barrier and are excreted in the urine after being absorbed into the systemic circulation. ${ }^{8}$ Quantitation of the probe in a timed urine collection provides a measure of the fraction of ingested probe that has penetrated the mucosal barrier. Only a small proportion of this large probe should get through the intestinal mucosa, reach the circulation, get filtered by the kidney and get measured in the urine over a defined point of time. If there is an abnormality in the paracellular transport; the passage of the probe is enhanced and thus more is excreted in the urine which suggests abnormality in the intestinal permeability. Intestinal permeability can be assessed using a variety of marker probes such as lactulose, mannitol, rhamnose and cellobiose, polyethylene glycol (PEG) 400, PEG 1000, ${ }^{51} \mathrm{Cr}$-EDTA and ${ }^{99 \mathrm{~m}}$ Tc-DTPA. The characteristics of these probes are summarized in Table 1.

\section{Single sugar test}

Earlier a single probe (such as lactulose, cellobiose, PEG and ${ }^{51} \mathrm{Cr}$-EDTA) was used to measure intestinal permeability. The urinary excretion of single dose of a test probe is dependent on a number of non-mucosal factors (such as gastric emptying, intestinal transit, renal clearance and incomplete urine recovery) other than the mucosal integrity itself, which not only reduce the sensitivity and specificity of test procedure, but also pose a problem in the interpretation of the data (Table 1).

\section{Differential sugar test}

To overcome the mucosal and non-mucosal factors (Table 2), Menzies ${ }^{7}$ suggested the use of two sugars or a combination of a sugar and non-sugar probe for assessment of intestinal permeability. It involves the simultaneous oral administration of disaccharide and monosaccharide and measurement of their excretion in urine over a defined period of time (Table 3). Intestinal permeability is measured as the ratio of percentage of excretion of

Table 1. Sugar Probes Used for Sugar Test

\begin{tabular}{|c|c|c|c|c|c|}
\hline Probes & Properties & Dose & Site of absorption & Techniques of measurement & Interpretation \\
\hline $\begin{array}{l}\text { Sucrose } \\
(\mathrm{MW} 342.2 \mathrm{Da})\end{array}$ & $\begin{array}{l}\text { Disaccharide, metabolized } \\
\text { beyond duodenum }\end{array}$ & $100 \mathrm{~g} / 24 \mathrm{hr}$ & & $\begin{array}{l}\text { Enzymatic assay and } \\
\text { Colorimetric assay HPLC }\end{array}$ & $\begin{array}{l}\text { Excretion is high in gastroduodenal } \\
\text { injury. }\end{array}$ \\
\hline $\begin{array}{l}\text { Lactulose } \\
\text { (MW } 342 \mathrm{Da})\end{array}$ & $\begin{array}{l}\text { Metabolized in the colon } \\
\text { by bacteria }\end{array}$ & $5 \mathrm{~g}$ & Small intestine & Enzymatic assay HPLC & $\begin{array}{l}\text { Lactulose excretion of urine is } \\
\text { high in small intestinal mucosal } \\
\text { disease. }\end{array}$ \\
\hline $\begin{array}{l}\text { PEG-400 } \\
(\mathrm{MW} 194-502 \mathrm{Da})\end{array}$ & $\begin{array}{l}\text { Hydrophilic, inert, } \\
\text { permeate through lipid } \\
\text { bilayer }\end{array}$ & $5-10 \mathrm{~g}$ & & HPLC & $\begin{array}{l}\text { Urinary excretion of PEG is } \\
\text { decreased in celiac disease. }\end{array}$ \\
\hline $\begin{array}{l}\text { Sucralose } \\
(\mathrm{MW} 397.64 \mathrm{Da})\end{array}$ & Chlorinated sucrose & $5-7.5 \mathrm{~g}$ & $\begin{array}{l}\text { Whole gut } \\
\text { (small intestine } \\
\text { and colon) }\end{array}$ & $\begin{array}{l}\text { Gas chromatography, thin } \\
\text { layer chromatography, } \\
\text { HPLC and Enzymatic assay }\end{array}$ & $\begin{array}{l}\text { Excretion is high in small intestinal } \\
\text { disease as well as in the disease } \\
\text { involving colon. }\end{array}$ \\
\hline $\begin{array}{l}{ }^{51} \mathrm{Cr}-\mathrm{EDTA} \\
(\mathrm{MW} 341.2 \mathrm{Da})\end{array}$ & Radiolabelled & $100 \mu \mathrm{Ci}$ & Whole gut & HPLC & $\begin{array}{l}\text { Increase urinary excretion in } \\
\text { inflammatory bowel disease. }\end{array}$ \\
\hline
\end{tabular}

PEG, polyethylene glycol; HPLC, high performance liquid chromatography. 
Table 2. Factors Affecting the Urinary Excretion of Marker Probes

\begin{tabular}{cl}
\hline \multicolumn{1}{c}{ Site } & Factors which can affect excretion of a probe \\
\hline Premucosal & Incomplete ingestion of test solution \\
& Vomiting \\
& Gastric emptying \\
& Intestinal degradation \\
& Dilution by secretion \\
Intestinal & Rate of transit \\
permeability & Mucosal area \\
& Mucosal permeability \\
& Systemic distribution \\
Disposal & Metabolism \\
& Renal clearance \\
& Urine collection \\
Analysis & Sample preservation \\
& Estimation \\
\hline
\end{tabular}

disaccharides/monosaccharides in the urine.

The individual variations due to the non-mucosal factors (such as gastric emptying, intestinal transit, renal clearance and incomplete urine recovery) are circumvented when the urinary recovery is expressed as a ratio (lactulose: mannitol ratio or LMR) since both of them are affected equally by these factors, except for the route of permeation. ${ }^{8}$ Any variation in premucosal and post mucosal determinants of the sugars affects overall permeation of the test probe equally, so that urinary excretion ratio (percentage of orally administered test dose) is not affected.

\section{Method of Assessment of Intestinal Permea- bility}

After an overnight fasting, subjects undergoing assessment of intestinal permeability are asked to ingest sugar probes ( $5 \mathrm{~g}$ of lactulose, $2 \mathrm{~g}$ of mannitol in $100 \mathrm{~mL}$ water for LMR) after voiding their first urine (which is collected). No food or drink is allowed until the completion of the test. Water intake is permitted after 1 hour from the ingestion of the test solution. All the subjects should be asked to drink a minimum of 1,000 $\mathrm{mL}$ of water during urine collection time to ensure sufficient urine output. All the urine passed in the subsequent 5 hours should be collected into a $2 \mathrm{~L}$ plastic container containing $1 \mathrm{~mL}$ of chlorohexidine $(20$ $\mathrm{mg} / \mathrm{mL}$ ) as a preservative. The volume of the urine is measured and a small volume $(10-100 \mathrm{~mL})$ is preserved and stored in $-80^{\circ} \mathrm{C}$ until analysis.

The concentration of one or more sugar probe present in the urine can be measured using enzyme assay, high performance liq-
Table 3. Differential Sugar Test Probes Used in Various Combinations

\begin{tabular}{ll}
\hline Sugar probes combination & \multicolumn{1}{c}{ Sites of permeation } \\
\hline Lactulose/mannitol & Used for small intestinal permeability \\
Lactulose/L-rhamnose & \\
Cellobiose/mannitol & \\
Cellobiose/mannitol & \\
${ }^{51}$ Cr-EDTA/mannitol & Used for whole gut permeability \\
Sucralose/mannitol & \\
Sucralose/L-rhamnose & \\
\hline
\end{tabular}

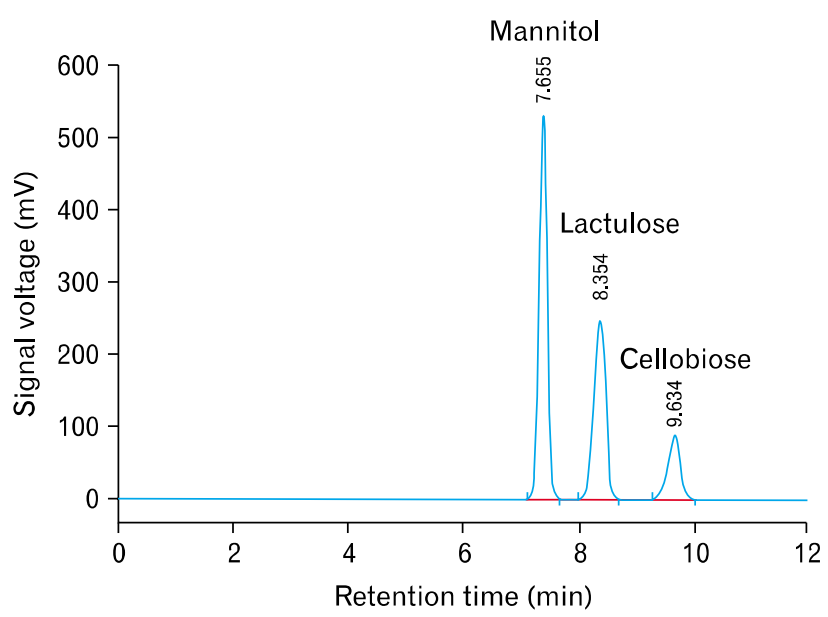

Figure. A high performance liquid chromatography chromatogram of lactulose and mannitol ratio. The chromatogram shows retention time of mannitol, lactulose and cellobiose. Cellobiose has been used as an internal control.

uid chromatography (HPLC), ion-exchange chromatography in combination with mass spectrometry and liquid chromatography with mass spectrometry. If the PEG has been used as a probe, then the concentration of the PEG can be assessed using capillary column gas chromatography.

Lactulose and mannitol ratio is the most commonly used test for assessment of intestinal permeability ${ }^{13}$ and the most reliable method of measurement of concentration of lactulose and mannitol in the urine is HPLC. HPLC is a chromatographic technique used to separate a mixture of compounds with the purpose of identifying, quantifying and purifying the individual components of the mixture. Small amount of urine sample is injected into a HPLC column which is filled with solid particles (called stationary phase) and the sample mixture is separated into compounds as it interacts with the column particles. These separated components are detected at the exit of this column by a flow- 
through device (detector) that measures their concentrations. An output from this detector is called a "liquid chromatogram." The separation of the components in the sample depends upon many parameters including chemical structure and molecular weight; but the most common parameter for the identification of individual compounds in the sample is its retention time (the time it takes to elute from the column after injection) (Figure). To measure the amount of solute (either lactulose or mannitol) in the urine sample, a standard curve is plotted by running the known amount of the solute and the amount of solute present in unknown sample is then estimated.

\section{Interpretation of Intestinal Permeability}

Urinary excretion of disaccharides and monosaccharides and ratio of their excretion is a basis of measurement for intestinal permeability. After the measurement of concentration of the probes in the urine; the results are expressed as the ratio of percentage excretion of the ingested dose of lactulose and mannitol in the urine ( $\mathrm{LMR}=\%$ lactulose $/ \%$ mannitol).

The lactulose and mannitol ratio is a useful, simple, non-invasive and a reliable test for estimation of intestinal permeability. ${ }^{13}$ In this test, while mannitol uses smaller and more numerous tight junctions at the villous tips mostly for its passage; lactulose being a larger molecule passes through larger pores in the crypts. Under normal physiological condition, disaccharide due to its large size is restricted from passing across the villous tip whereas monosaccharides can do so with relative freedom. The sizes of probe and pore in the intestinal mucosa have a bearing on the abnormalities in the permeability among different disease conditions. Since patients with Crohn's disease do not generally have diffuse villous atrophy, the mannitol excretion remains unaffected in them, while the excretion of mannitol is affected greatly in celiac disease where villous atrophy is the hallmark. Loss of villi leads to loss of smaller tight junctions at the villous tips affecting excretion of smaller probes such as mannitol. ${ }^{4}$ Therefore, an increased intestinal permeability observed in patients with Crohn's disease is predominantly because of the increase in permeation of lactulose.

\section{Normal Values for Lactulose and Mannitol Excretion in the Urine}

Every laboratory should have their cut off values for the lactulose mannitol ratio. The percentage excretion of lactulose and mannitol in healthy volunteers at our center is 0.3550 (range
0.0204-1.8030) and 12.300 (range 1.4800-43.7500), respectively. The median LMR ratio in healthy controls at our center is 0.0317 (range 0.0029-0.2510). ${ }^{14}$

\section{Clinical Relevance of Intestinal Permeability Testing}

Testing of intestinal permeability is not required for routine patient care, however it is an important tool to understand the function of the paracellular transport in the research setting. There are a number of diseases that have been known to arise as a consequence of an increase in mucosal permeation of macromolecules.

\section{Intestinal permeability in various disorders}

Food allegy. It is hypothesized that altered intestinal permeability allows increase in permeation of dietary antigen transport across intestine and exposure of dietary antigen to mucosal immune system, leading to development of the dietary antigen-specific response.

Celiac disease. It is an enteropathy triggered by gluten specific $\mathrm{T}$ cell mediated immune response in genetically susceptible organism. Altered intestinal barrier function and an increase in intestinal permeability has been implicated in the pathogenesis of celiac disease. ${ }^{13}$ Studies on Irish setter dogs, naturally occurring gluten sensitivity model, have shown that an increase in intestinal permeability exists even prior to onset of this autoimmune disease in them. ${ }^{15}$ Majority of treatment naïve patients with celiac disease have abnormal intestinal permeability. While withdrawal of gluten improves both clinical and histological abnormalities, it also normalizes the paracellular function and hence the intestinal permeability in them.

Crohn's disease. Thirty-three to $68 \%$ of patients with Crohn's disease have been reported to have an increase in intestinal permeability. ${ }^{16}$ There are evidences which suggest that there is a correlation between the intestinal permeability and activity of the disease, ${ }^{17}$ especially in Crohn's disease.

Type 1 diabetes. Increase in intestinal permeability is also found in type 1 diabetes. An increase in the intestinal permeability have been shown to exist even prior to onset of type 1 diabetes ${ }^{18}$ both in the family members of diabetes and in the experimental studies of the bio-breeding diabetic prone rats. ${ }^{19}$ The abnormality in the intestinal permeability even prior to onset if diabetes suggests its role in the pathophysiology of type I diabetes. 
Screening of the high risk groups. Measurement of intestinal permeability has been a useful technique to study the increase in the susceptibility to a few autoimmune diseases in a high risk group, such as first degree relative of celiac disease and Crohn's disease. A girl found to have an increase in intestinal permeability while asymptomatic during the family screening study, developed Crohn's disease 8 years later. ${ }^{20}$

\section{Conclusion}

Overall assessment of paracellular route of transport can be assessed by measurement of intestinal permeability. Different probes (sugar and EDTA), having different area of absorption/metabolism, can be used to study the permeability of the specific area of the gastrointestinal tract. This test is not required for day to day patient's diagnosis and management; however, it is an important tool which helps in the study of the early phases of pathophysiology of many diseases such as celiac disease, Crohn's disease, type I diabetes and food allergy.

\section{References}

1. Cereijido M, Ponce A, Gonzalez-Mariscal L. Tight junctions and apical/basolateral polarity. J Membr Biol 1989;110:1-9.

2. Bjarnason I, MacPherson A, Hollander D. Intestinal permeability: an overview. Gastroenterology 1995;108:1566-1581.

3. Travis S, Menzies I. Intestinal permeability: functional assessment and significance. Clin Sci (Lond) 1992;82:471-488.

4. Fihn BM, Sjöqvist A, Jodal M. Permeability of the rat small intestinal epithelium along the villus-crypt axis: effects of glucose transport.Gastroenterology 2000;119:1029-1036.

5. McCance RA, Madders K. The comparative rates of absorption of sugars from the human intestine. Biochem J 1930;24:795-804.

6. Fordtran JS, Rector FC Jr, Ewton MF, Soter N, Kinney J. Permeability characteristics of the human small intestine. J Clin Invest 1965;44:1935-1944.

7. Menzies IS. Transmucosal passage of inert molecules in health and disease. In: Skadhauge E, Heintze K, eds. Intestinal absorption and secretion. Lancaster: MTP Press 1984:527-543.

8. Uil JJ, van Elburg RM, van Overbeek FM, Mulder CJ, VanBerge-Henegouwen GP, Heymans HS. Clinical implications of the sugar absorption test: intestinalpermeability test to assess mucosal barrier function. Scand J Gastroenterol 1997;32(suppl 223):70-78.

9. Kawabata H, Meddings JB, Uchida Y, Matsuda K, Sasahara K, Nishioka M. Sucrose permeability as a means of detecting diseases of the upper digestive tract. J Gastroenterol Hepatol 1998;13:1002-1006.

10. Müller M, Walker-Smith J, Shmerling DH, Curtius HC, Prader A. Lactulose: a gas-liquid chromatography method of determination and evaluation of its use to assess intestinal mucosal damage. Clin Chim Acta 1969;24:45-49.

11. Oliva A, Armas H, Fariña JB. HPLC determination of polyethylene glycol 400 in urine: oligomeric profile in healthy and celiac disease subjects. Clin Chem 1994;40:1571-1574.

12. Jenkins RT, Ramage JK, Jones DB, Collins SM, Goodacre RL, Hunt RH. Small bowel and colonic permeability to $51 \mathrm{Cr}$-EDTA in patients with active inflammatory bowel disease. Clin Invest Med 1988;11:151-155.

13. Juby LD, Rothwell J, Axon AT. Lactulose/mannitol test: an ideal screen for celiac disease. Gastroenterology 1989;96:79-85.

14. Benjamin J, Makharia GK, Ahuja V, Kalaivani M, Joshi YK. Intestinal permeability and its association with the patient and disease characteristics in Crohn's disease. World J Gastroenterol 2008;14: 1399-1405.

15. Hall EJ, Batt RM. Abnormal permeability precedes the development of a gluten sensitive enteropathy in Irish setter dogs. Gut 1991;32: 749-753.

16. Peeters M, Ghoos Y, Maes B, et al. Increased permeability of macroscopically normal small bowel in Crohn's disease. Dig Dis Sci 1994; 39:2170-2176.

17. Wyatt J, Vogelsang H, Hübl W, Waldhöer T, Lochs H. Intestinal permeability and the prediction of relapse in Crohn's disease. Lancet 1993;341:1437-1439.

18. Bosi E, Molteni L, Radaelli MG, et al. Increased intestinal permeability precedes clinical onset of type 1 diabetes. Diabetologia 2006; 4928:24-27.

19. Neu J, Reverte CM, Mackey AD, et al. Changes in intestinal morphology and permeability in the biobreeding rat before the onset of type 1 diabetes. J Pediatr Gastroenterol Nutr 2005;40:589-595.

20. Irvine EJ, Marshall JK. Increased intestinal permeability precedes the onset of Crohn's disease in a subject with familial risk. Gastroenterology 2000;119:1740-1744. 